
upf. $\begin{array}{ll}\text { Universitat } & \text { Department } \\ \text { Pompeu Fabra } & \text { of Economics and Business }\end{array}$ Barcelona

Economics Working Paper Series

Working Paper No. 1620

\title{
Gender norms and intimate partner violence
}

Libertad González and Núria Rodríguez-Planas

October 2018 


\title{
Gender Norms and Intimate Partner Violence
}

\author{
Libertad González \\ Universitat Pompeu Fabra and Barcelona GSE \\ Núria Rodríguez-Planas \\ City University of New York (CUNY), Queens College
}

\section{October 2018}

\begin{abstract}
We study the effect of social gender norms on the incidence of domestic violence. We use data for 28 European countries from the 2012 European survey on violence against women, and focus on first and second generation immigrant women. We find that, after controlling for country of residence fixed effects, as well as demographic characteristics and other source-country variables, higher gender equality in the country of ancestry is significantly associated with a lower risk of victimization in the host country. This suggests that gender norms may play an important role in explaining the incidence of intimate partner violence.
\end{abstract}

JEL codes: I1, J6, D1

Keywords: domestic violence, gender, social norms, immigrants, epidemiological approach.

\footnotetext{
We thank the European Union Agency for Fundamental Rights for making the dataset (European FRA survey on violence against women) available to us. We thank Paul Vertier and participants at the 7th Annual Conference on "Immigration in OECD Countries", and the 2018 IZA World Labor conference in Berlin for excellent comments on the paper. González acknowledges financial support from the Spanish Ministry of Economy and Competitiveness, through the Severo Ochoa Program for Centres of Excellence in R\&D (SEV2015-0563). Authors' contact: Libertad González, Universitat Pompeu Fabra, Department of Economics and Business, Ramon Trias Fargas 25-27, 08005 Barcelona, Spain. Email: libertad.gonzalez@upf.edu. Núria Rodríguez-Planas, Queens College - CUNY, Economics Department, Powdermaker Hall, 65-30 Kissena Blvd., Queens, New York 11367, USA. Email: nuria.rodriguezplanas@qc.cuny.edu.
} 
"Violence against women is not a small problem that only occurs in some pockets of society, but rather is a global public health problem of epidemic proportions, requiring urgent action. As recently endorsed by the Commission on the Status of Women, it is time for the world to take action: a life free of violence is a basic human right, one that every woman, man, and child deserves."

World Health Organization, 2013.

\section{Introduction}

In Europe, one in five women report having been victims of physical and/or sexual violence at some point in their life, and three fourths of them report that violence was perpetrated by an intimate partner or ex-partner. The incidence of reported intimate partner violence during the previous 12 months varies widely across EU countries, from 3\% in Slovenia to 33\% in Belgium or Denmark (FRA 2014), and the disparity widens when one looks at other continents, from $1 \%$ in Singapore to $40 \%$ in Ethiopia (United Nations 2015). On top of the well-documented injuries and health problems that result directly from violence against women ${ }^{1}$, psychological and emotional wounds may well generate medium- to long-term problems affecting women's employment (Browne et al. 1999; Lloyd and Taluc 1999) and well-being, with deeper consequences for their families-including their children's health and development-, and society as a whole (WHO 2002). Hence, understanding the determinants of intimate partner violence, a global public health problem, is of fundamental importance.

This paper studies whether traditional gender norms might be a key factor in explaining the incidence and intensity of intimate partner violence (IPV thereafter). In patriarchal societies, men are the breadwinners while women specialize in childrearing and domestic tasks, making men the dominant group and putting women in a position of dependency on their husbands. Such economic dependency may make women less likely to adopt economic or social sanctions against potentially abusive husbands (Choi and Ting 2008), or less likely to leave an abusive relationship (Tauchen, Witte and Sharn 1991; Vyas and Watts 2009). At the same time, in societies where violence against women is more common or where a substantial proportion of individuals condone abuse, women's risk of experiencing, accepting, or rationalizing IPV may be higher (Garcia-Moreno et al. 2005; WHO 2009). As societies change, with women's role moving outside of the household, and

${ }^{1}$ Health outcomes include but are not limited to HIV infection, sexually transmitted infections, induced abortion, low birth weight, premature birth, growth restriction in utero and/or children with small for gestational age, alcohol use, depression and suicide, injuries, and death from homicide (WHO 2013). 
men and women converging in human capital investments, employment, and wages, gender roles evolve and women (and men) may be less likely to internalize social norms that justify abuse. To the extent that traditional gender norms determine the incidence and intensity of IPV, policies aiming at transforming gender relations should be an important focus of prevention efforts.

To identify whether traditional gender norms have a causal effect on the risk of IPV, we face the following three challenges: how to achieve causal identification (the identification strategy), and the measurement of both the outcome and key explanatory variables, namely IPV and traditional gender norms.

Our identification strategy draws from a recent literature that emphasizes the relevance of individuals' cultural background by exploiting country-of-ancestry variation in measures of gender equality to identify the effect of "culture" on behavioral outcomes for first- and second-generation immigrants ${ }^{2}$ (Antecol 2000 and 2001; Fernández and Fogli 2006 and 2009; Blau et al. 2013; Nollenberger, Rodríguez-Planas and Sevilla 2016; RodríguezPlanas and Sanz-de-Galdeano 2016; Rodríguez-Planas and Nollenberger 2018). ${ }^{3}$ In this context, culture is defined as "beliefs and preferences that vary systematically across groups of individuals separated by space (either geographic or social) or time", in our case regarding women's role in society (Fernández 2008). Because first- and second-generation immigrants live in the same host country ${ }^{4}$, they share their host country's laws and institutions, but differ in their cultural background. We exploit variation in measures of gender equality across countries of ancestry (as proxies for gender-related norms) to identify the effect of traditional gender norms on the incidence and intensity of IPV among first- and second-generation women, holding constant a battery of individual and partner controls, as well as other country-of-ancestry macro-level factors, that may affect partner violence for reasons unrelated to gender social norms. Following Nollenberger, Rodríguez-Planas and

\footnotetext{
${ }^{2}$ First-generation immigrants are those who migrated to the host country. Second-generation immigrants are those who were born in the country their parents migrated to.

3 Antecol (2000 and 2001) analyzes the effect of gender social norms on labor force participation and wages, respectively. Fernández and Fogli (2006 and 2009) and Blau et al. (2013) explore the effect of culture on female labor force participation and fertility. Nollenberger, Rodríguez-Planas and Sevilla (2016) and Rodríguez-Planas and Nollenberger (2018) study the effect of gender social norms on the math gender gap (the former) and the math, science and reading gender gaps (the latter), whereas Rodríguez-Planas and Sanz-deGaldeano (2016) study the effect of gender social norms on smoking.

${ }^{4}$ In the case of second-generation immigrants, host country refers to the host country their parents migrated to.
} 
Sevilla (2016), we proxy traditional gender norms in the source country with the 2009 World Economic Forum's gender gap index (GGI), which measures women's economic and political opportunities, education, and well-being, relative to those of men. ${ }^{5,6}$ Our findings are robust to using other measures of gender norms in the country of ancestry.

According to Heise and Kotsadam (2015), one of the biggest challenges for studies exploring country- or state-level predictors of partner violence is to find reliable and homogenous measures of intimate partner violence as, frequently, different surveys are used for different countries that vary in terms of violence questions, methods, and ethical controls. We are able to circumvent this challenge by using the 2012 European Union (EU) Fundamental Rights Agency (FRA) household survey on violence against women, which collects women's experiences of physical, sexual and psychological violence in 28 EU countries. From this dataset, we restrict our analysis to the subsample of first- and secondgeneration immigrant women, coming from 41 different countries of ancestry, and we were able to access restricted information on the country of birth of the parents of survey respondents. Using country of ancestry, we merge our individual-level survey responses with the GGI and other national-level statistics compiled from the United Nations, the OECD and the World Bank.

In our baseline specification, we find that one standard deviation increase in countryof-ancestry (log) GGI is associated with a decline in the incidence of IPV of 1.4 percentage points (or a $29 \%$ decrease with respect to the mean), and a fall in the intensity of IPV of 0.053 (or a $48 \%$ decrease relative to the mean). In our most restrictive specifications, one standard deviation increase in country-of-ancestry $(\log )$ GGI is associated with a decline in the incidence of IPV of $15 \%$ of the mean, and with a fall in the intensity of IPV of $33 \%$. Our results are robust to a battery of sensitivity tests.

Recently, several researchers have focused on identifying which macro-level genderrelated factors are associated with the cross-country variation in IPV (Farmer and Tiefenthaler 1997; Garcia-Moreno et al. 2005; Fulu et al. 2013; Heise and Kotsadam, 2015;

\footnotetext{
${ }^{5}$ This is the same index used by Guiso et al. (2008) and Fryer and Levitt (2010) in ecological studies analyzing whether the math gender gap decreases with gender equality. RodríguezPlanas and Sanz de Galdeano (2016) and Rodríguez-Planas and Nollenberger (2018) also use the country-of-ancestry GGI as in the current paper.

${ }^{6}$ Antecol (2000 and 2001) uses country-of-ancestry gender gaps in labor force participation and wages as proxies of social gender norms, respectively; whereas Fernández and Fogli (2006 and 2009) and Blau et al. (2013) use country-of-ancestry female labor force participation and fertility.
} 
Cools and Kotsadam 2017) or violence against women more broadly (Bott, Morrison, and Ellsberg 2005; Palma-Solis et al. 2008). These studies suggest a relationship between societal factors in gender-related domains and IPV. ${ }^{7}$ While these findings are noteworthy, they encounter at least two challenges that our analysis aims at addressing. First, earlier studies are unable to separate correlation from causality as they suffer simultaneity (or reverse causation) bias. To put it differently, while it is plausible that greater gender equality leads to a reduction in IPV, an alternative interpretation could be that in countries where women suffer less IPV, they also have more respect and self-esteem, easier access to (well) paid labor force, and greater emancipatory demands, leading to the creation of institutions that discriminate less against them. Note that in our analysis, this simultaneity bias is less likely as it is difficult to argue that immigrant women (first-generation) or daughters of immigrants (second-generation) are likely to affect gender norms and institutions in their country of birth or that of their parents.

Second, most studies analyzing different macro-level correlates of IPV focus on which formal institutions-namely laws, regulations and policies, institutional factors, economic conditions, and socio-economic characteristics - explain violence against women, as opposed to informal institutions or "culture"—namely "those customary beliefs and values that ethnic, religious, and social groups transmit fairly unchanged from generation to generation" (Guiso, Sapienza, and Zingales 2006), such as beliefs regarding women's role in society. Hence, our second contribution is to provide evidence on the extent to which the transmission of beliefs (culture), as opposed to institutions per se, determines a woman's risk of suffering IPV. While our analysis is silent to whether institutions matter ${ }^{8}$, our finding that country-of-ancestry gender equality is directly related to the risk of IPV in the host country underscores the role of cultural attitudes versus that of a country's institutions and formal practices, informing a public health policy issue of first-order importance.

\footnotetext{
${ }^{7}$ Our analysis complements a well-developed literature on the individual life-course factors that determine whether a couple will experience violence, namely, genetic predisposition, developmental pathways, and partner-related factors (see Abramsky et al. 2011 and references within). To the extent possible our analysis controls for individuals' developmental pathways, as well as partner-related factors.

${ }^{8}$ Others have studied the role of institutions on IPV using quasi-experimental methods. In such studies, institutions include unilateral divorce laws, mandatory arrest laws, or better police and law enforcement against violence against women (Stevenson and Wolfers 2006; Iyengar 2009; Iyer et al. 2012), the gender wage gap (Aizer 2010); or unemployment (TurPrats 2017).
} 
Three notable and insightful related studies are Tur-Prats (2015), Alesina, Brioschi and La Ferrara (2106), and Heise and Kotsadam (2015). Tur-Prats (2015) finds evidence of lower prevalence of IPV today in Spanish territories with higher prevalence of stem families(two generations cohabitating in the household) in the past. Similarly, Alesina, Brioschi and La Ferrara (2106) find that certain pre-colonial norms about marriage patterns, living arrangements, and the productive role of women in the African continent are associated with contemporary violence against women. Finally, Heise and Kotsadam (2015) study whether contemporaneous norms related to wife beating and male authority over women are associated with IPV. They find that, while these macro-level norms matter in ecological models, they lose statistical significance once they control for (potentially endogenous) individual-level factors, such as whether the woman accepts wife beating as a man's right. Heise and Kotsadam conclude that: "An inherent problem in all macro-level analyses is to separate correlation from causality. We do not claim causality for any of the correlations presented here. (...) We urge future studies (...) to disentangle the causal association between variables where possible." Our work contributes to this literature using recently available data collected across 28 European countries and covering 41 countries of ancestry.

\section{Data}

Our main data source is the 2012 European Union (EU) Fundamental Rights Agency (FRA) household survey on violence against women, conducted between March and September 2012. Using women's country of ancestry, we merged these individual-level data with national-level indices of gender equality from the 2009 World Economic Forum. These are a composite of four different indices: economic opportunity, political empowerment, educational attainment, and health and survival, and they range from 0 to 1 , with larger values indicating a better position of women in society. Alternatively, we use other measures of gender equality to proxy country of ancestry gender norms, namely the prevalence of physical violence against women by an intimate partner from the United Nations, the female labor force participation (FLFP) from the International Labour Organization (ILO), and gender-related norms regarding male authority and control, gender discrimination in ownership index, and family law, from the OECD Development Center. Appendix Table A1 presents a detailed description of all macro-level variables used in the analysis, as well as basic descriptive statistics and their data sources. 
The 2012 FRA EU-wide survey collected women's experiences of physical, sexual and psychological violence by partners and non-partners in 28 EU countries. The survey, administered using either CAPI or $\mathrm{PAPI}^{9}$, was carried out using face-to-face interviews, which took place either in the respondent's home or in another place of her choosing, and reassured her of the confidentiality of her responses. All interviewers were female and had a minimum of three months' experience in random probability survey work, in addition to extensive training on interviewing on sensitive questions.

To be eligible, respondents had to be females between the ages of 18 and 74, residents of one of the $28 \mathrm{EU}$ Member States, and able to speak at least one of the official languages of the country. ${ }^{10}$ To ensure that every eligible female resident of the Member State had a reasonable chance of being included in the sample, sampling frames were selected using a random method. The sampling was based on a two-stage clustered stratified design with equal probability of selection for households within clusters. As the first stage, primary sampling units (PSUs) were selected for this survey with probability proportional to size (PPS). As the second stage, a set number of addresses was randomly selected with a view to conducting a maximum of 30 interviews within the PSU. While all residents within a household had a chance of being included in the sample, only one eligible respondent, selected using a random method, was interviewed. The interviews lasted between 30 minutes and an hour, with most interviews being close to three quarters of an hour. The response rate was $77.3 \%$ (FRA European Union Agency for Fundamental Rights 2014).

We focus our analysis on the effects of social gender norms on IPV, both at the extensive and intensive margins. To do so, we define the following two outcome variables: a binary indicator for whether a woman experienced any physical aggression from a current or previous partner during the previous twelve months, and a measure of the intensity of IPV,

\footnotetext{
${ }^{9}$ CAPI stands for computer assisted personal interviewing, and PAPI for pen and paper interviewing. ${ }^{10}$ Less than $1 \%$ of people contacted were unable to take part because they did not speak one of the languages. As this was a household survey, persons living in institutions or homeless were excluded. ${ }^{11}$ We also consider measures of IPV that include sexual in addition to physical violence. Our main results are driven by physical violence. Results that include sexual violence are available upon request.

${ }^{10}$ Less than $1 \%$ of people contacted were unable to take part because they did not speak one of the languages. As this was a household survey, persons living in institutions or homeless were excluded. ${ }^{11} \mathrm{We}$ also consider measures of IPV that include sexual in addition to physical violence. Our main results are driven by physical violence. Results that include sexual violence are available upon request.
} 
computed as the sum of different types of physical aggression to which the woman may have been exposed during the twelve months prior to the survey (by current or previous partner). ${ }^{11}$ The intensive margin indicator ranges between 0 to 10 . Table 1 lists the different types of physical aggression that our outcome variables cover, and Appendix Table A2 shows the incidence and intensity of IPV in our sample across host countries. Finally, we also control for a battery of individual- and partner-level socio-demographic characteristics, which are summarized in Appendix Table A3.

\section{Sample Restrictions and Descriptive Statistics}

Because of strict data confidentiality reasons, the FRA does not share information on parents' country of birth for women with parents born outside the host country. We succeeded in getting the FRA to share these data with us as long as there were at least 10 cases of individuals with a parent born in a particular foreign country in each host country. ${ }^{12}$ After applying this restriction, our sample comprises 3,609 immigrant women for whom we have information on the country of birth of their parents.

If parents' country of birth was different and the mother was born in the host country (or mothers' country of birth was not available), the FRA gave us the father's country of birth. For all other cases, the FRA gave us the mother's country of birth. Prioritizing mothers' country of birth is consistent with findings that mother's culture is more relevant for females than father's culture (Blau et al. 2013).

First- and second-generation ${ }^{13}$ women in our sample come from 41 different countries of ancestry, and live in 22 different EU countries (as shown in Appendix Tables A2 and

\footnotetext{
${ }^{11}$ We also consider measures of IPV that include sexual in addition to physical violence. Our main results are driven by physical violence. Results that include sexual violence are available upon request.

${ }^{12}$ Dropping immigrants whose country of ancestry has fewer than 10 observations in a given host country is common practice in this literature (Fernandez and Fogli 2006; Nollenberger, Rodríguez-Planas and Sevilla 2016). ${ }^{13}$ Using a similar methodological approach some studies focus on immigrants (Carroll, Rhee \& Rhee 1994; and Furtado, Marcen and Sevilla 2013) or both first- and second-generation immigrants (Osili and Paulson 2008; and Luttmer and Singhal 2011, Rodríguez-Planas 2018).

${ }^{13}$ Using a similar methodological approach some studies focus on immigrants (Carroll, Rhee \& Rhee 1994; and Furtado, Marcen and Sevilla 2013) or both first- and second-generation immigrants (Osili and Paulson 2008; and Luttmer and Singhal 2011, Rodríguez-Planas 2018).
} 
A4). ${ }^{14}$ Second-generation immigrants represent $45 \%$ of our sample (1,631 individuals). The countries of ancestry in our sample cover several continents and different levels of development, with many European countries (25) and some transition economies (such as Poland and Russia), several countries in the Americas (including Argentina and Brazil), and some in Asia (including China, India and Pakistan) and Africa (such as Morocco or Tunisia). The most common countries of ancestry are Russia, Bosnia, Portugal and Germany. The host countries with the highest sample of immigrants are Estonia, Latvia, Luxembourg and Croacia (immigrants living in these countries represent $50 \%$ of our sample).

In our sample, $4.8 \%$ of woman report having suffered IPV during the previous 12 months, and the indicator of intensity averages 0.11 (see Appendix Table A3). We observe wide variation in the incidence as well and the intensity of IPV across countries of both residence (Appendix Table A2) and ancestry (Appendix Table A4). The incidence and intensity of IPV in our sample of immigrants are similar to those observed for first- and second-generation migrants for which we do not observe parents' country of ancestry $(5.1 \%$ and 0.12 on average). IPV is slightly lower among native women, with an average incidence of $3.9 \%$ and average intensity of 0.09 .

Appendix Table A4 also shows that there is considerable dispersion in gender equality in the country of ancestry, as the GGI ranges from 0.55 in Pakistan to 0.84 in Norway. Appendix Table A5 shows the correlation between the incidence and intensity of IPV in the host country and different measures of gender equality in the country-of-ancestry. Figures 1 and 2 plot our measures of incidence and intensity of IPV in our sample of immigrants versus the GGI in the country of ancestry, our main indicator of gender equality. Overall, the raw data show that the more gender equality in the country of ancestry, the lower the incidence and intensity of IPV immigrant women experience in the host country. The regression lines have slopes of -0.86 and -0.30 , with a standard error of 0.30 and $0.17 .^{15}$

\footnotetext{
${ }^{14}$ Because we had no information on parent's country of birth for six host countries (Bulgaria, Cyprus, Finland, Greece, Poland, and Romania), this restriction led us to limit our analysis to $22 \mathrm{EU}$ countries.

${ }^{15}$ Results are similar if we drop the outlier (Tunisia) in Figure 2 (see Appendix Figure A1).
} 


\section{Methods}

To examine whether country-of-ancestry gender social norms affect the likelihood of experiencing intimate partner violence, we estimate the following multivariate fixed-effects linear regression on our sample of immigrant women:

$$
V_{i j k}=\alpha_{0}+\alpha_{1} \ln G G I_{j}+X_{i j k}^{\prime} \alpha_{2}+Z_{j}^{\prime} \alpha_{3}+\lambda_{k}+\varepsilon_{i j k}
$$

where $V_{i j k}$ is our indicator of incidence (or intensity) of IPV experienced by woman $i$ from country of ancestry $j$ and living in host country $k$. Our main macro-level variable of interest, $\ln G G I_{j}$, is the natural logarithm of the gender gap index in country of ancestry $j$. The vector $X_{i j k}^{\prime}$ includes a set of individual and partner characteristics. The vector $Z_{j}^{\prime}$ includes a set of country-of-ancestry measures such as the GDP per capita (in logs), the literacy rate, the GINI coefficient, the legal system, and/or the property rights index in the country of ancestry. Both vectors $Z_{j}$ and $X_{i j k}$ vary with the specification considered and aim at controlling for factors that may affect violence against women for reasons unrelated to culture. To account for characteristics of the country of residence that may be related to IPV, we include a full set of dummies for host country $k\left(\lambda_{k}\right)$. Our coefficient of interest, $\alpha_{1}$, captures the association between gender gaps in the country of ancestry and the experience of IPV in the host country. Standard errors are clustered at the country-of-ancestry level, which is the level of aggregation of our main explanatory variable. While equation (1) is estimated with OLS, our results are robust to using probit for the incidence of IPV, and negative binomial for the intensity of IPV.

Data limitations lead us to use contemporaneous measures of gender equality-as opposed to at the time when individuals (or their parents) emigrated. ${ }^{16}$ Whether it is best to use contemporaneous or lagged measures is unclear, as countries' beliefs about the role of women in society change slowly over time and "the values that parents and society transmit are best reflected in what their contemporaneous counterparts are doing in the country of ancestry" (Fernández and Fogli 2009). Measuring social gender norms with error because of their timing would lead to attenuation bias, and hence underestimate the impact of culture, making our estimates a lower bound for the effect of social gender norms.

\footnotetext{
${ }^{16}$ The use of contemporaneous measures is common in the literature (Giuliano, 2007; Fernández and Fogli, 2009; Furtado, Marcen and Sevilla, 2013; and Nollenberger, Rodríguez-Planas, Sevilla, 2016; among others).
} 


\section{Results}

\section{Micro-level Covariates}

Table 2 presents the main results from estimating different empirical specifications of equation 1, in which additional micro-level covariates are sequentially included in the regression. The analysis is done separately for the incidence and the intensity measures of IPV, and shown in the first and second rows of Table 2, respectively. Each column and row represents a separate regression on IPV.

The model in column 1 only controls for host-country fixed effects and the countryof-ancestry GGI. The negative coefficients for GGI in both regressions (-0.252, and -0.929$)$ confirm that IPV is negatively correlated with gender equality in the country of ancestry, both at the extensive and intensive margins. Both coefficients are statistically significant at the $1 \%$ level. Because women's risk of IPV may depend on her human capital accumulation ${ }^{17}$ (Fulu et al. 2013) and this may vary systematically across countries of ancestry, the model in column 2 controls for women's completed education, and is our baseline specification. While controlling for educational attainment reduces a tad our coefficients of interest $(-0.237$ and -0.889$), \alpha_{1}$ remains negative and statistically significant at both margins.

The interpretation of our findings follow: one standard deviation increase in countryof-ancestry log GGI is associated with a decrease in the incidence of IPV of 1.4 percentage points (or a $29 \%$ decrease with respect to the mean) ${ }^{18}$ and a decrease in the intensity of IPV of 0.053 events (or a $48 \%$ decrease relative to the mean). ${ }^{19}$ Column 3 shows that our findings hold even when we use a different functional form, namely a Probit for the incidence indicator and a negative binomial for the intensity indicator.

In what follows, we sequentially add individual- and partner-level socio-demographic controls to the baseline model, to explore the robustness of this finding. Some of these

\footnotetext{
.${ }^{17}$ Women's educational attainment reflects both her labor market and marriage opportunities and is directly related to her socio-economic background (Fulu et al. 2013). ${ }^{18}$ Using estimates from column 2 in Table 2, these values are calculated as follows: $\quad \alpha_{1}(-0.237) * \log G G I_{s t d}(0.06)=-0.014$, and $\frac{-0.014}{\text { Incidence }_{\text {mean }}(0.049)}=-0.29$.

18 Using estimates from column 2 in Table 2, these values are calculated as follows: $\alpha_{1}(-0.237) * \log G G I_{s t d}(0.06)=-0.014$, and $\frac{-0.014}{\text { Incidence }_{\text {mean }}(0.049)}=-0.29$.

19 Using estimates from column 2 in Table 2, these values are calculated as follows: $\alpha_{1}(-0.889) * \log G G I_{\text {std }}(0.06)=-0.053$ and $\frac{-0.053}{\text { Incidence }_{\text {mean }}(0.11)}=-0.48$.
} 
controls are endogenous (potentially affected by gender norms themselves), so that by including these additional individual- and partner-level characteristics, we are testing whether gender social norms have a "direct" impact on IPV, beyond the indirect ways in which these other variables could affect domestic violence. In other words, by including some of these additional (potentially endogenous) controls, we are restricting the channels through which culture is allowed to affect IPV.

Column 4 presents a model that saturates the specification with individual-level controls by including age, family structure, labor force status, household income, rural versus urban residence of the respondent, and whether the woman was born in the survey country or not. The reasons for including such controls is that they may be related to the odds of being an IPV victim in the survey country for reasons unrelated to gender-domains in the country of ancestry, but that vary systematically across countries of ancestry in such a way that relates with gender equality. For instance, suffering domestic violence may be related to a particular birth cohort, which could vary systematically across countries of ancestry if certain cohorts come from more gender unequal countries of ancestry. Also, many have found that being married or cohabitating, having children, working (or not), household's income, living in rural areas, or being foreign born, are correlated with the risk of suffering IPV (Fulu et al. 2013). As family structure, work status, household's income or geographic location within the survey country may vary systematically across countries of ancestry, not controlling from them could bias our estimates of the effect of culture.

Adding these controls reduces our main coefficients of interest, by half in the case of the incidence of IPV and by one third in the case of the intensity of IPV, consistent with earlier studies showing the relevance of individual life-course factors. Nonetheless, $\alpha_{1}$ remains sizeable, negative and statistically significant at the 5\% level, supporting the hypothesis that experiencing domestic violence in the host country is related to the situation of women in the country of ancestry. Column 5 shows that our findings are robust to alternative functional forms even when all individual-level controls are included in the specification.

We can compare how gender social norms affect IPV in relation to other variables, for instance, in relation to having children. The specification shown in column 4 in Table 2 allows us to do so. We find that one standard deviation increase in country-of-ancestry log 
GGI is associated with a decrease in the intensity of IPV of 0.037 (or 33\%). ${ }^{20}$ Having children is associated with an increase of IPV of 0.107 . Hence, we find that the effect of gender social norms on the intensity of domestic violence is about one third that of having children. Because our measure is a lower bound, our analysis seems to suggest that social gender norms are quite important in explaining IPV, strengthening earlier findings by Heise and Kotsadam (2015) on the relevance of gender-equitable norms.

The model in column 6 addresses concerns that IPV is related to partner characteristics by controlling for partner's educational attainment and employment status. Interestingly, doing so has little effect on our coefficients of interest, which are now -0.130 and $-0.638 .{ }^{21}$ Similarly, the models in columns 7 and 8 address concerns that we may be capturing discrimination against immigrants from certain (more gender unequal) countries of ancestry. Column 7 presents a model that includes as a control a dummy for whether the woman considers herself part of a minority group, and column 8 a model with a dummy for whether the woman reports having experienced discrimination in the host country. While we find that women experiencing discrimination also experience more violence $(0.043$, std error $=0.015$, the effect of country-of-ancestry GGI on IPV is barely affected in both models (compared to our model in column 4), suggesting that being a minority or discriminated against is not driving our results.

\section{Macro-level Covariates}

Table 3 explores whether the effect of gender social norms on IPV is mediated or driven by alternative macro-level characteristics of the country of ancestry. Note that we only want to control for macro-level factors that may affect violence against women for reasons unrelated to discrimination against women. The reason being that any gender-related reason for IPV is already captured by the GGI, which is a widely defined index capturing gender gaps in the labor market, the educational system, politics, health, and wellbeing.

The model in column 1 of Table 3 replicates our baseline model from Table 2 in column 2. Column 2 in Table 3 adds to our baseline model the log GDP per capita of the source country. The concern is that by omitting this variable, we are mainly picking up

${ }^{20}$ Using estimates from column 4 in Table 2, these values are calculated as follows: $\alpha_{1}(-0.613) * \log G G I_{\text {std }}(0.06)=0.037$ and $\frac{0.037}{\text { Incidence }_{\text {mean }}(0.11)}=0.33$.

${ }^{21}$ The survey lacks information on the nationality of the partner, preventing us from controlling for partner's immigration status. ${ }^{22}$ Using estimates from column 2 in Table 3, these values are calculated as follows: $\alpha_{1}(-0.107) * \log G G I_{\text {std }}(0.06)=0.006$, and $\frac{0.006}{\text { Incidence }_{\text {mean }}(0.049)}=0.12$. 
systematic wealth differences across immigrants from different ancestries. Indeed, adding log GDP per capita into our model reduces our coefficients of interest by more than half (0.107 and -0.40), and we lose precision. Despite losing statistical significance of our main coefficient of interest, we still find that one standard deviation increase in country-of-ancestry $\log$ GGI is associated with a decrease in the incidence of IPV of 0.6 percentage points (or a $12 \%$ decrease relative ti the mean), ${ }^{22}$ and with a decrease in the intensity of IPV of 0.024 (22\% of the mean). ${ }^{23}$ As explained by Heise and Kottayam (2015), it is likely that the GDP per capita is picking up economic growth and modernization, and hence complex social processes that frequently accompany transformations in women's roles in societies. To put it differently, to the extent that differences in economic development across countries of ancestry also affect the cultural attitude towards women in these societies, we may well be over-controlling.

Column 3 in Table 3 presents our baseline model controlling for the country-ofancestry literacy level instead. While doing so reduces the coefficient of interest by two fifths at the extensive margin and close to one third at the intensive margin, both estimates remain negative (although the effect is no longer significant at the extensive margin). Columns 4 adds to our baseline model a control for country-of-ancestry legal systems, which reflects the strength of legal rights and the institutional quality in the country of ancestry (La Porta et al. 1999). Columns 5 includes instead an index of property rights, which measures the degree to which a country's laws protect private property rights, and the degree to which its government enforces those laws and its judiciary system is independent. While controlling for country-of-ancestry legal systems has little effect on our coefficient of interest, controlling for property rights in the country of ancestry reduces the impact of gender-related culture on the incidence of IPV by close to two thirds, and on the intensity of IPV by close to one third. Nonetheless, in both models the effect of gender-related culture on IPV remains statistically significant at the $10 \%$ level or lower.

The model in column 6 includes all macro-level controls that were statistically significant when included one by one in our baseline model. This model captures differences in country-of-ancestry gender-related culture beyond those due to differences in the economic

${ }^{22}$ Using estimates from column 2 in Table 3, these values are calculated as follows: $\alpha_{1}(-0.107) * \log G G I_{\text {std }}(0.06)=0.006$, and $\frac{0.006}{\text { Incidence }_{\text {mean }}(0.049)}=0.12$.

${ }^{23}$ Using estimates from column 2 in Table 3 , these values are calculated as follows: $\alpha_{1}(-0.400) * \log G G I_{s t d}(0.06)=0.024$ and $\frac{0.024}{\text { Incidence }_{\text {mean }}(0.11)}=0.22$. 
development and institutional quality that may affect domestic violence for reasons unrelated to gender equality in the country of ancestry. To the extent that these differences also affect the cultural attitude towards gender, we may well be over-controlling.

We find that one standard deviation increase in country-of-ancestry log GGI is associated with a decrease in the intensity of IPV of $0.025(23 \%){ }^{24}$ The effect on the incidence of IPV is half the size than in our baseline model, and is no longer statistically significant. Even though the effect on the incidence of IPV becomes statistically nonsignificant when controlling for country-of-ancestry economic growth and strength of legal rights and the institutional quality, it is plausible that we are over-controlling as economic and legal institutions affect how societies differentially treat its citizens based on many dimensions, including gender. To the extent that the level of economic development or the quality of the institutions come hand in hand with social processes that erode norms and beliefs in male superiority, and social stigmas on women's paid employment or access to education and economic assets, by including them into the model we are testing whether gender social norms have a direct impact on IPV beyond the indirect ways in which these other variables could affect domestic violence.

\section{Alternative Measures of Gender-Related Culture}

Table 4 explores which institutions in the country of ancestry shape the social norms regarding gender that end up affecting IPV in the host country. In addition, this exercise explores the sensitivity of our findings to alternative proxies of culture. Each row displays the effect of one standard deviation increase in the gender-related domain used in each regression on the incidence of IPV (shown in column 1) and the intensity of IPV (shown in column 3). Columns 2 and 4 show the statistical significance of $\alpha_{1}$ in each case. Results are displayed in this manner to simplify comparison across gender-related measures.

Rows 2 to 5 use one of the four indices composing the GGI instead of the composite (which is shown in the first row and is our baseline model). All eight estimates of $\alpha_{1}$ are negative, indicating that greater gender equality in economic power, education, political empowerment, or health and wellbeing are associated with lower IPV in the host country. All but one of the coefficients are statistically significant at the 5\% level or lower. The following two rows use female labor force participation and the prevalence of IPV in the

${ }^{24}$ Using estimates from column 6 in Table 3, these values are calculated as follows: $\alpha_{1}(-0.410) * \log G G I_{\text {std }}(0.06)=0.025$ and $\frac{0.025}{\text { Incidence }_{\text {mean }}(0.11)}=0.23$. 
country of ancestry as alternative proxies of culture. Again, the results are consistent with our main findings. Greater female labor force participation and lower IPV prevalence in the country of ancestry are associated with lower IPV in the host country. In the model using IPV prevalence as explanatory variable, we lose precision as data restrictions limit the number of countries of ancestry used and, hence, reduce the sample size.

Following Heise and Kotsadam (2015), in row 8 we use a direct measure of genderrelated norms from the Gender, Institutions and Development 2014 Data Base from OECD International Development, namely the percentage of women who agree that a husband/partner is justified in beating his wife/partner under certain circumstances. In the last two rows, we use two measures of discrimination against women: one pertaining to family law, and the other to ownership. Because these institutions are measured at the country-of-ancestry level, we are not directly capturing their effect on IPV in the host country, but instead we are capturing which institutions in the country of ancestry appear to be shaping the gender norms that are related to IPV in the host country. In all three models we find that our coefficients of interest are positive indicating that greater acceptance of IPV or gender discrimination in family law or ownership in the country of ancestry correlate with a higher incidence and intensity of IPV in the host country, consistent with our earlier findings. Small sample sizes reduce the precision of our estimates in certain cases. With the exception of row 8 , estimates of $\alpha_{1}$ remain statistically significantly different from zero at the $10 \%$ or lower.

Comparing the size of the effect for the different gender-related domains in Table 4 reveals that gender norms related to women's relative educational attainment seem to matter the most, followed by gender norms related to women's relative health and wellbeing, as well as discrimination against women's ownership, and to a lower extent family-law discrimination.

\section{Selection Bias}

Table 5 presents some additional sensitivity analysis. Column 1 replicates our baseline specification. Column 2 adds to our baseline specification the country-of-ancestry Gini index. We do so to address potential concerns that our results would suffer from selection bias as immigrants' decision to migrate and where to migrate to might be a function of both their own unobserved ability, and country-of-ancestry and host-country distribution of income (Borjas, 1987). In our specification shown in column 2 of Table 5, the coefficient on the Gini index is close to zero and not statistically significant (not shown), providing no 
evidence that immigrants from countries of ancestry with greater inequality are more (or less) likely to experience IPV than those coming from more equal countries. Importantly, our estimated coefficients of interest $\left(\alpha_{1}\right)$ remain similar to those in our baseline model.

The next four columns re-estimate our baseline specification removing from the sample immigrants coming from Russia (column 3) and Bosnia (column 4), and those residing in Estonia (column 5) and Latvia (column 6). Doing so leaves our key coefficient essentially unaffected, suggesting that our main findings are not driven by the two largest groups of immigrants (those from Russia and Bosnia in our sample), or those living in the host countries with more observations in our data set (Estonia and Latvia in our case).

\section{Heterogeneity}

To explore whether the transmission of cultural beliefs on the role of women in society varies across different types of immigrants, Table 6 shows results from estimating our baseline specification for different subgroups. Columns 1 and 2 explore whether the effect varies with the respondent's educational attainment, columns 3 and 4 by whether the respondent has any children, and columns 5 and 6 by whether the respondent was born in the host country (second-generation) or migrated to the host country (first-generation). While we find that the effect of culture holds for all subgroups, our findings on incidence are stronger for low educated women, whereas those on intensity are driven by women with children. Finding that culture persists more among immigrants with children is consistent with findings from Luttmer and Singhal (2011) on the effects of country-of-ancestry preferences on preferences for redistribution, as well as Rodríguez-Planas (2018) on the effects of financial culture on mortgage debt.

We find that the effect of gender-related culture holds for both first- and secondgeneration immigrants, and the size of the effect is similar for both subgroups. Findings that culture persists among second-generation immigrants suggest that vertical transmission (from parents to children) may be at work. Consistent with this, Antecol (2000), Fernandez and Fogli (2006), Giuliano (2004), Nollenberger, Rodríguez-Planas, and Sevilla (2016) and Rodríguez-Planas (2018) also find that culture persist across generations.

\section{Conclusions}

Violence against women is a serious public health issue with traumatic consequences for the women who experience it and their families. Violence against women is often perpetrated by an intimate partner or previous partner. Hence, better understanding the factors affecting 
intimate partner violence (IPV) is a first step into designing policies aiming at reducing domestic violence. This paper studies whether traditional gender norms are a key factor in explaining the incidence and intensity of IPV. To do so, we exploit country-of-ancestry variation in measures of gender equality, which proxy gender social norms for immigrant women. While immigrants live in the same host country, and hence, share their host country's laws and institutions, as well as economic conditions, they differ in their cultural background. Finding that gender norms in the country of ancestry are associated with domestic violence in the host country suggests that gender-related culture affects violence against women.

Our analysis shows that the higher the degree of gender equality in the country of ancestry, the lower the incidence and intensity of IPV experienced by women in the host country, suggesting that more gender-equitable culture affects women's individual risk of domestic violence. This finding holds for a wide range of variables capturing gender norms. Crucially, because these gender-related macro-level domains are measured in the country-ofancestry, while women's risk of violence occurs in the host country, and holding constant women's and their partners' socio-demographic characteristics, our findings underscore the relevance of inter-generational transmission of gender social norms for women's experience of domestic violence. This is a step forward in disentangling the causal association between gender equality and IPV. Our finding that the results are as strong for second-generation as for first-generation immigrants suggest that gender-related culture persists over time and across generations.

One caveat of our identification approach is that, if we were to find non-statistically significant results, we could not conclude that (gender-related) culture does not affect IPV. Instead, it would only mean that our measures of gender social norms may not be capturing well enough gender-related culture in the country of ancestry. As most of our estimates are statistically significant, this is not an issue in our analysis. Nonetheless, because it is likely that gender social norms in the country of ancestry are measured with error, it is important to highlight that our approach most likely delivers an underestimate of the effect of culture on IPV. Moreover, as our approach only captures the effect of culture from the country of ancestry, ignoring gender norms from the host country, our findings are indicative that gender-related culture matters, but it only provides lower bounds of the size of the effect.

Our analysis does not shed light on how formal institutions affect IPV. However, as North (1990) explains, understanding the role of informal institutional constraints is 
fundamental to guide policy making on modifying formal institutions. Finding that gender norms related to women's relative educational attainment matter, as well as gender norms related to women's relative health and wellbeing and discrimination against women's ownership, provides policy guidance regarding which formal institutions ought to be modified as a strategy to reduce IPV. Improving female literacy and female educational attainment might be an effective strategy to modify gender social norms such that domestic violence is reduced. Similar to Heise and Kotsadam (2015), we also find that removing barriers to women's access to land and property may help reduce intimate partner violence levels. However, the mechanism may not necessarily be direct, but may take place via changing gender-related culture or social norms. Perhaps not surprisingly, our findings also underscore the relevance of pushing for policies that reduce the gap between women and men's healthy life expectancy, and tackle the phenomenon of "missing women". Finally, equalizing women's and men's rights regarding parental authority after divorce may also be a potential strategy to change gender norms that in turn may reduce domestic violence. 


\section{References}

Abramsky T, Watts CH, Garcia-Moreno C. Karen Devries, Ligia Kiss, Mary Ellsberg, Henrica AFM Jansen, and Lori Heise. 2011. "What Factors are Associated with Recent Intimate Partner Violence? Findings from the WHO Multi-Country on Women's Health and Domestic Violence." BMC Public Health. 2011; 11: 109. Published online 2011 Feb 16. doi: 10.1186/1471-2458-11-109

Alesina A., B. Brioschi, E. La Ferrara. 2016. "Violence Against Women: A Cross-cultural Analysis for Africa.” NBER Working Paper No. 21901. Issued in January 2016.

Antecol, H. 2000. "An Examination of Cross-Country Differences in the Gender Gap in Labor Force Participation Rates." Labour Economics, 7(4): 409-26.

Antecol, H. 2001. Why is there interethnic variation in the gender wage gap?: The role of cultural factors. Journal of Human Resources, 36(1): 119-143.

Aizer A. 2010. "The Gender Wage Gap and Domestic Violence", American Economic Review, 100, 1847-1859.

Blau, Francine D., Lawrence M. Kahn, AlbertYung-Hsu Liu, and Kerry L. Papps. 2013. "The Transmission of Women's Fertility, Human Capital, and Work Orientation across Immigrant Generations." Journal of Population Economics 26(2): 405-35. http://dx.doi.org/10.1007/s00148-012-0424-X.

Bott S., Morrison A., and Ellsberg M. 2005. "Preventing and Responding to Gender-Based Violence in Middle- and Low-Income Countries: a Multi-Sectoral Literature Review and Analysis." e-library, World Bank Group. http://dx.doi.org/10.1596/1813-9450$\underline{3618 .}$

Browne A., Salomon A., and Bassuk SS. 1999. "The Impact of Recent Partner Violence on Poor Women's Capacity to Maintain Work.” Violence against Women, 5: 393-426.

Carroll, Christopher D., Byung-Kun Rhee, and Changyong Rhee. 1994. "Are There Cultural Effects on Saving? Some Cross-Sectional Evidence." The Quarterly Journal of Economics 109(3): 685-99.

Choi, S. Y., \& Ting, K. F. 2008. Wife beating in South Africa: An imbalance theory of resources and power. Journal of Interpersonal Violence, 23, 834-852.

Cools, S., and Kotsadam, A. 2017. Resources and intimate partner violence in Sub-Saharan Africa. World Development. Volume 95, 211-230.

Farmer A. and Tiefenthaler J. 1997. "An Economics Analysis of Domestic Violence." Review of Social Economy, 55 (3): 337-358.

Fernández, Raquel. 2008. "Culture and Economics.” New Palgrave Dictionary of Economics, 2nd edition.

Fernández, Raquel, and Alessandra Fogli. 2006. Fertility: The Role of Culture and Family Experience. Journal of the European Economic Association, 4(2-3): 552-61.

Fernández, Raquel, and Alessandra Fogli. 2009. Culture: An Empirical Investigation of Beliefs, Work, and Fertility. American Economic Journal: Macroeconomics, 1(1): 146-77. 
FRA European Union Agency for Fundamental Rights 2014. "Violence Against Women: An EU-wide Survey: Survey Methodology, Sample and Field Work" ISBN 978-929239-273-4 doi:10.2811/67959.

FRA European Agency for Fundamental Rights. 2015. "Violence Against Women: an EUwide Survey. Main Results.” ISBN 978-92-9239-999-3 doi:10.2811/981927 TK-0113-850-EN-3.

Fryer, Ronald, and Steven Levitt. 2010. "An Empirical Analysis of the Gender Gap in Mathematics.” American Economic Journal: Applied Economics 2(2): 210-40.

Furtado, Delia, Miriam Marcén, and Almudena Sevilla. 2013. "Does Culture Affect Divorce? Evidence from European Immigrants in the United States." Demography 50(3): 101338.

Fulu, Emma \& MD Prof. Rachel Jewkes, MBBS \& Tim Roselli, BSc \& Claudia GarciaMoreno, MD. (2013). "Prevalence of and factors associated with male perpetration of intimate violence: findings from the UN Multi-country Cross-sectional Study on Men and Violence in Asia and the Pacific." Lancet, 1(4): 187-207.

Garcia-Moreno, Jansen, Ellsberg, Heise and Watts. 2005. WHO Multi-Country Study on Women's Health and Domestic Violence against Women: Initial Results on Prevalence, Health Outcomes, and Women's Responses. Technical report, Geneva: World Health Organization.

Giuliano, Paola. 2007. "Living Arrangements in Western Europe: Does Cultural Origin Matter?" Journal of the European Economic Association 5(September): 927-52.

Guiso, Luigi, Ferdinando Monte, Paola Sapienza, and Luigi Zingales. 2008. "Culture, Gender, and Math." Science (New York, N.Y.) 320: 1164-65.

Guiso, Luigi, Paola Sapienza and Luigi Zingales. 2006. "Does Culture Affect Economic Outcomes?" Journal of Economic Perspectives, 20(2): 23-48.

Heise L., and Kotsadam A., 2015. "Cross-National and Multilevel Correlates of Partner Violence: an Analysis of Data from Population-Based Surveys." Lancet Glob Health; 3: e332-40.

Lloyd S., Taluc N. 1999. "The Effects of Male Violence on Female Employment." Violence against Women, 5: 370-392.

Iyengar, R. 2009. "Does the certainty of arrest reduce domestic violence? Evidence from mandatory and recommended arrest laws." Journal of Public Economics, 93(1-2):8598.

Iyer L., A. Mani, P. Mishra and P. Topalova. 2012. “The Power of Political Voice: Women's Political Representation and Crime in India." American Economic Journal: Applied Economics, vol 4:4: 165-93.

LaPorta, R., F. Lopez-de-Silanes, Andrei Shleifer, and R. W Vishny, 1999. "The Quality of Government", Journal of Law, Economics and Organization, 15:1, 222-279. 
Luttmer, Erzo F. P, and Monica Singhal. 2011. "Culture, Context, and the Taste for Redistribution.” American Economic Journal: Economic Policy 3(1): 157-79.

Nollenberger, N., N. Rodríguez-Planas, and A. Sevilla. 2016. "The Math Gender Gap: The Role of Culture." American Economic Review, vol. 106, no. 5, pp. 257-61.

North, D. 1990. Institutions, Institutional Change, and Economic Performance. New York: Cambridge University Press.

Osili U., and A Paulson, 2008. "Institutions and Financial Development: Evidence from International Migrants in the United States," Review of Economics and Statistics. 90(3): 498-512.

Palma-Solis M., Vives-Cases C., Alvarez-Dardet C. 2008. "Gender Progress and Government Expenditure as a Determinants of Femicide." Ann Epidemiology, 18: 322-29.

Rodríguez-Planas N. 2018. "Mortgage Finance and Culture.” Journal of Regional Science, 58 (4): 786-821. DOI: 10.1111/jors.12385.

Rodríguez-Planas N. and N. Nollenberger. 2018. "Let the Girls Learn! It's not Only about Math... It is About Gender Social Norms." Economics of Education Review. Vol. 62: $230-253$.

Rodríguez-Planas N. and Sanz-de-Galdeano A. 2016. "Social Norms, and Teenage Smoking: The Dark Side of Gender Equality.” IZA working paper 10134, August 2016.

Stevenson, B., Wolfers, J. (2006). Bargaining in the Shadow of the Law: Divorce Laws and Family Distress. The Quarterly Journal of Economics, Volume 121, Issue 1, 267-288.

Tauchen, H. V., Witte, A. D., and Long, S. K. (1991). Domestic Violence: A Nonrandom Aff air. International Economic Review, 32(2):491-511.

Tur-Prats, A. (2015). "Family Types and Intimate- Partner Violence: A Historical Perspective". Working Papers 835, Barcelona Graduate School of Economics.

Tur-Prats (2017). Unemployment and Intimate-Partner Violence: A Gender-Identity Approach. Barcelona GSE Working Paper Series. Working Paper $\mathrm{n}^{\circ} 963$.

United Nations, 2015. The World's Women 2015: Trends and Statistics. New York: United Nations, Department of Economic and Social Affairs, Statistics Division.

Vyas, S. and Watts, C. (2009). How does economic empowerment aff ect women's risk of intimate partner violence in low and middle income countries? a systematic review of published evidence. Journal of International Development, 21(5):577-602.

Warnock V., \& Warnock, F. (2008). Markets and Housing Finance. Journal of Housing Economics, 17(3), 239-251.

World Health Organization. 2002. World Report on Violence and Health. World Health Organization, Department of Reproductive Health and Research. ISBN 9241545615.

World Health Organization. 2009. Changing Cultural and Social Norms that Support Violence, Technical report, Series of briefings on violence prevention: the evidence. 
World Health Organization. 2013. Global and regional estimates of domestic violence against women: prevalence and health effects of intimate partner violence and nonpartner sexual violence. Geneva: World Health Organization, Department of Reproductive Health and Research. ISBN 9789241564625. 
Table 1. Intimate Physical Violence by Current or Previous Partner in the Past 12Months

Could you please tell me how often have you experienced any of the following by any current or previous partner in the past 12 months:

Threatened to hurt you physically

Pushed you or shoved you

Slapped you

Threw a hard object at you

Grabbed you or pulled your hair

Beat you with a fist or a hard object, or kicked you

Burned you

Tried to suffocate you or strangle you

Cut or stabbed you, or shot at you

Beat your head against something

Source: 2012 European Union (EU) Fundamental Rights Agency (FRA) household survey on violence against women. Questions E04 and G04. 
Figure 1. Raw Incidence of IPV among Immigrants and Gender Equality in their Countries of Ancestry

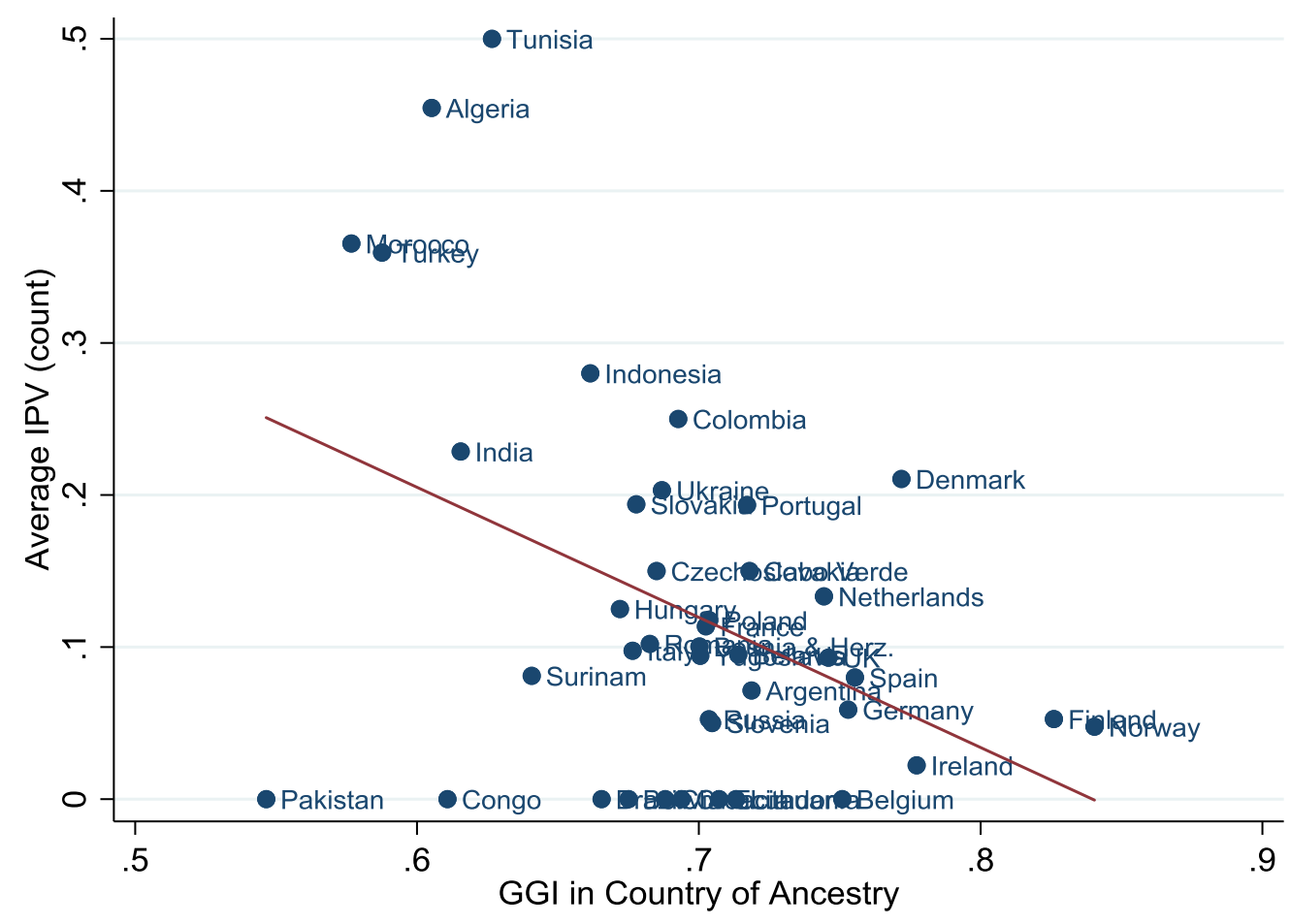

Notes: Figure 1 displays the correlation between the raw incidence of IPV among immigrants and the GGI in their countries of ancestry. Each variable is an average by country-ofancestry, across all host countries. The regression line has a slope of -0.8558 with a standard error of 0.2976 . 
Figure 2. Raw Average Number of IPV Events among Immigrants and Gender Equality in their Countries of Ancestry

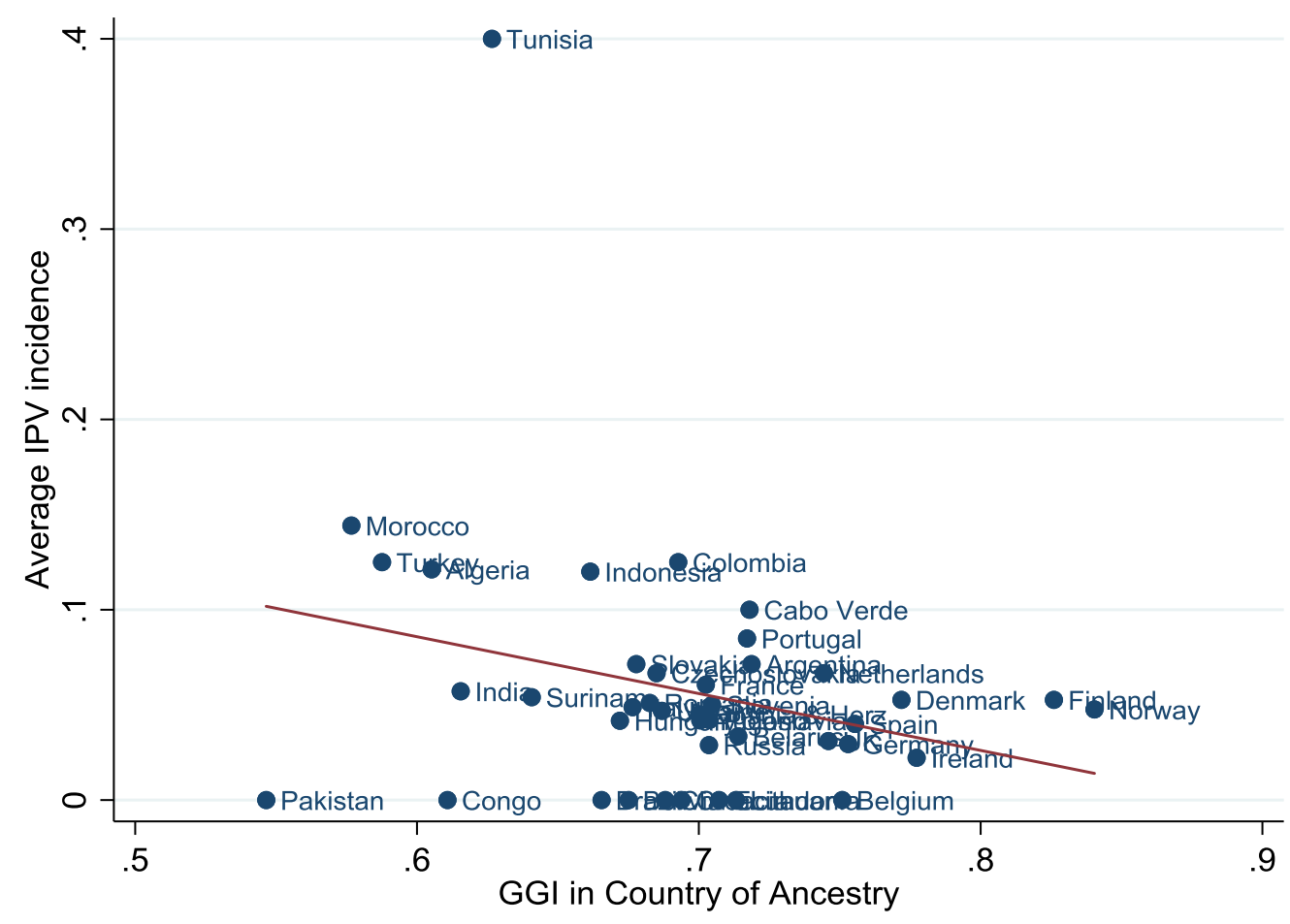

Notes: Figure 2 displays the correlation between the raw count of IPV incidents among immigrants in the host country and the GGI in their countries of ancestry. Each variable is an average by country-of-ancestry, across all host countries. The regression line has a slope of 0.2987 with a standard error of 0.1694 . 
Table 2. Country-of-Ancestry GGI and Incidence and Intensity of Intimate Partner Physical Violence in the Past 12 Months

\begin{tabular}{|c|c|c|c|c|c|c|c|c|}
\hline & $\begin{array}{c}\text { No } \\
\text { controls }\end{array}$ & $\begin{array}{c}\text { Highest } \\
\text { educational } \\
\text { attainment }\end{array}$ & $\begin{array}{l}\text { Alternative } \\
\text { functional } \\
\text { form }\end{array}$ & $\begin{array}{l}\text { Individual } \\
\text { controls }\end{array}$ & $\begin{array}{l}\text { Alternative } \\
\text { functional } \\
\text { form }\end{array}$ & $\begin{array}{l}\text { Partner } \\
\text { controls }\end{array}$ & $\begin{array}{l}\text { Minority } \\
\text { control }\end{array}$ & Discrimination \\
\hline & $(1)$ & $(2)$ & $(3)$ & $(4)$ & (5) & $(6)$ & $(7)$ & $(8)$ \\
\hline $\begin{array}{l}\text { Experienced violence } \\
\text { (binary variable) }\end{array}$ & $\begin{array}{c}-0.252 * * * \\
(0.0617)\end{array}$ & $\begin{array}{c}-0.237 * * * \\
(0.061)\end{array}$ & $\begin{array}{c}-1.716^{* * *} \\
(0.356)\end{array}$ & $\begin{array}{c}-0.122 * * \\
(0.058)\end{array}$ & $\begin{array}{l}-0.709 * \\
(0.411)\end{array}$ & $\begin{array}{c}-0.130 * * \\
(0.059)\end{array}$ & $\begin{array}{l}-0.112 * \\
(0.058)\end{array}$ & $\begin{array}{c}-0.122 * * \\
(0.056)\end{array}$ \\
\hline $\begin{array}{l}\text { Number of times } \\
\text { experienced violence } \\
\text { (continuous variable) }\end{array}$ & $\begin{array}{c}-0.929 * * * \\
(0.177)\end{array}$ & $\begin{array}{c}-0.889 * * * \\
(0.178)\end{array}$ & $\begin{array}{c}-5.796^{* * *} \\
(1.144)\end{array}$ & $\begin{array}{c}-0.613 * * * \\
(0.185)\end{array}$ & $\begin{array}{c}-3.807 * * * \\
(1.290)\end{array}$ & $\begin{array}{c}-0.638 * * * \\
(0.190)\end{array}$ & $\begin{array}{c}-0.598 * * * \\
(0.191)\end{array}$ & $\begin{array}{c}-0.612 * * * \\
(0.179)\end{array}$ \\
\hline Observations & 3,609 & 3,609 & 3,609 & 3,609 & 3,609 & 3,609 & 3,609 & 3,609 \\
\hline $\begin{array}{l}\text { Host-country fixed } \\
\text { Effects }\end{array}$ & $\mathrm{Y}$ & $\mathrm{Y}$ & $\mathrm{Y}$ & $\mathrm{Y}$ & Y & $\mathrm{Y}$ & $\mathrm{Y}$ & $\mathrm{Y}$ \\
\hline Education controls & $\mathrm{N}$ & $\mathrm{Y}$ & $\mathrm{Y}$ & Y & $\mathrm{Y}$ & $\mathrm{Y}$ & $\mathrm{Y}$ & $\mathrm{Y}$ \\
\hline $\begin{array}{l}\text { Age } \\
\text { Second-generation }\end{array}$ & $\mathrm{N}$ & $\mathrm{N}$ & $\mathrm{N}$ & $\mathrm{Y}$ & $\mathrm{Y}$ & $\mathrm{Y}$ & $\mathrm{Y}$ & $\mathrm{Y}$ \\
\hline immigrant & $\mathrm{N}$ & $\mathrm{N}$ & $\mathrm{N}$ & $\mathrm{Y}$ & $\mathrm{Y}$ & Y & $\mathrm{Y}$ & Y \\
\hline cohabitating & $\mathrm{N}$ & $\mathrm{N}$ & $\mathrm{N}$ & $\mathrm{Y}$ & $\mathrm{Y}$ & $\mathrm{Y}$ & $\mathrm{Y}$ & $\mathrm{Y}$ \\
\hline $\begin{array}{l}\text { Presence of children } \\
\text { Works outside of }\end{array}$ & $\mathrm{N}$ & $\mathrm{N}$ & $\mathrm{N}$ & $\mathrm{Y}$ & $\mathrm{Y}$ & $\mathrm{Y}$ & $\mathrm{Y}$ & $\mathrm{Y}$ \\
\hline household & $\mathrm{N}$ & $\mathrm{N}$ & $\mathrm{N}$ & $\mathrm{Y}$ & Y & $\mathrm{Y}$ & $\mathrm{Y}$ & $\mathrm{Y}$ \\
\hline Lives in rural area & $\mathrm{N}$ & $\mathrm{N}$ & $\mathrm{N}$ & $\mathrm{Y}$ & $\mathrm{Y}$ & $\mathrm{Y}$ & $\mathrm{Y}$ & $\mathrm{Y}$ \\
\hline Household's income & $\mathrm{N}$ & $\mathrm{N}$ & $\mathrm{N}$ & $\mathrm{Y}$ & $\mathrm{Y}$ & $\mathrm{Y}$ & $\mathrm{Y}$ & $\mathrm{Y}$ \\
\hline $\begin{array}{l}\text { In a relationship } \\
\text { Partner's educational }\end{array}$ & $\mathrm{N}$ & $\mathrm{N}$ & $\mathrm{N}$ & $\mathrm{N}$ & $\mathrm{N}$ & $\mathrm{Y}$ & $\mathrm{N}$ & $\mathrm{N}$ \\
\hline attainment & $\mathrm{N}$ & $\mathrm{N}$ & $\mathrm{N}$ & $\mathrm{N}$ & $\mathrm{N}$ & $\mathrm{Y}$ & $\mathrm{N}$ & $\mathrm{N}$ \\
\hline Partner works & $\mathrm{N}$ & $\mathrm{N}$ & $\mathrm{N}$ & $\mathrm{N}$ & $\mathrm{N}$ & $\mathrm{Y}$ & $\mathrm{N}$ & $\mathrm{N}$ \\
\hline Is a minority & $\mathrm{N}$ & $\mathrm{N}$ & $\mathrm{N}$ & $\mathrm{N}$ & $\mathrm{N}$ & $\mathrm{N}$ & $\mathrm{Y}$ & $\mathrm{N}$ \\
\hline
\end{tabular}


Notes: OLS coefficient estimates and their associated standard errors clustered by country of ancestry in parentheses.

Columns 3 and 5 use instead of the OLS, a Probit model for the binary left-hand-side variable and a negative binomial model for the continuous variable (number of events).

$* * * \mathrm{p}<0.01, * * \mathrm{p}<0.05, * \mathrm{p}<0.1$ 
Table 3. Sensitivity of Results to Adding Country-of-Ancestry Aggregate Controls

\begin{tabular}{|c|c|c|c|c|c|c|}
\hline & $\begin{array}{c}\text { Baseline } \\
\text { model }\end{array}$ & & & & & \\
\hline & (1) & (2) & (3) & (4) & (5) & (6) \\
\hline $\begin{array}{l}\text { Experienced violence } \\
\text { (binary variable) }\end{array}$ & $\begin{array}{c}-0.237 * * * \\
(0.061)\end{array}$ & $\begin{array}{l}-0.107 \\
(0.078)\end{array}$ & $\begin{array}{l}-0.135 \\
(0.084)\end{array}$ & $\begin{array}{c}-0.237 * * * \\
(0,070)\end{array}$ & $\begin{array}{l}-0.165^{*} \\
(0.087)\end{array}$ & $\begin{array}{l}-0.103 \\
(0.071)\end{array}$ \\
\hline $\begin{array}{l}\text { Number of times experienced violence } \\
\text { (continuous variable) }\end{array}$ & $\begin{array}{c}-0.889 * * * \\
(0.178)\end{array}$ & $\begin{array}{l}-0.400 * \\
(0.239)\end{array}$ & $\begin{array}{c}-0.635^{* *} \\
(0.251)\end{array}$ & $\begin{array}{c}-0.903 * * * \\
(0.199)\end{array}$ & $\begin{array}{c}-0.623 * * \\
(0.245)\end{array}$ & $\begin{array}{l}-0.410 * \\
(0.243)\end{array}$ \\
\hline Observations & 3,609 & 3,609 & 3,609 & 3,609 & 3,609 & 3,609 \\
\hline
\end{tabular}

\begin{tabular}{|c|c|c|c|c|c|c|}
\hline Host-country fixed effects & $\mathrm{Y}$ & $\mathrm{Y}$ & $\mathrm{Y}$ & $\mathrm{Y}$ & $\mathrm{Y}$ & $\mathrm{Y}$ \\
\hline Women's education & $\mathrm{Y}$ & $\mathrm{Y}$ & $\mathrm{Y}$ & $\mathrm{Y}$ & $\mathrm{Y}$ & $\mathrm{Y}$ \\
\hline Country of ancestry log gdp x capita & $\mathrm{N}$ & $\mathrm{Y}$ & $\mathrm{N}$ & $\mathrm{N}$ & $\mathrm{N}$ & Y \\
\hline Country of ancestry literacy rate & $\mathrm{N}$ & $\mathrm{N}$ & $\mathrm{Y}$ & $\mathrm{N}$ & $\mathrm{N}$ & $\mathrm{N}$ \\
\hline Country of ancestry legal system & $\mathrm{N}$ & $\mathrm{N}$ & $\mathrm{N}$ & $\mathrm{Y}$ & $\mathrm{N}$ & $\mathrm{Y}$ \\
\hline Country of ancestry property rights & $\mathrm{N}$ & $\mathrm{N}$ & $\mathrm{N}$ & $\mathrm{N}$ & $\mathrm{Y}$ & $\mathrm{N}$ \\
\hline
\end{tabular}


Table 4. Changes Between Country-of-Ancestry Measures of Gender Equality and IPV in the Host Country

\begin{tabular}{|c|c|c|c|c|c|c|}
\hline \multirow{3}{*}{$\begin{array}{l}\text { One standard deviation increase in: } \\
\text { The following measure of country-of- } \\
\text { ancestry gender equality } \\
\text { log GGI }\end{array}$} & \multicolumn{4}{|c|}{ Affects IPV in the host country by: } & \multirow{3}{*}{$\begin{array}{c}\text { \# observations } \\
\\
3,609\end{array}$} & \multirow{3}{*}{ \# clusters } \\
\hline & \multicolumn{2}{|c|}{$\begin{array}{l}\text { Incidence } \\
\text { (in percent) }\end{array}$} & \multicolumn{2}{|c|}{$\begin{array}{l}\text { Intensity } \\
\text { (in counts) }\end{array}$} & & \\
\hline & $-4 \%$ & $* * *$ & -0.16 & $* * *$ & & \\
\hline log Economic Power Index & $-4 \%$ & $* * *$ & -0.13 & $* * *$ & 3,609 & 41 \\
\hline log Education Index & $-73 \%$ & $* *$ & -2.57 & $* * *$ & 3,609 & 41 \\
\hline log Health Index & $-25 \%$ & & -1.21 & $* *$ & 3,609 & 41 \\
\hline log Political Empowerment Index & $-0.77 \%$ & $* * *$ & -0.03 & $* * *$ & 3,609 & 41 \\
\hline Female Labor Force Participation & $-2.40 \%$ & $* * *$ & -0.15 & $* * *$ & 3,609 & 41 \\
\hline $\begin{array}{l}\text { Aggregate IPV } \\
\% \text { women who agree IPV can be }\end{array}$ & $1.96 \%$ & $*$ & 0.14 & $*$ & 2,150 & 32 \\
\hline justified & $0.91 \%$ & & 0.12 & & 3,552 & 39 \\
\hline Family Law Discrimination & $14.93 \%$ & $*$ & 0.65 & $* *$ & 3,552 & 39 \\
\hline Ownership Discrimination & $24.34 \%$ & $* *$ & 0.89 & $* * *$ & 3,552 & 39 \\
\hline
\end{tabular}

Notes: Results from separate baseline regressions with different measures of country-of-ancestry gender-related domains as indicated in the first column.

$* * * \mathrm{p}<0.01, * * \mathrm{p}<0.05, * \mathrm{p}<0.1$ 
Table 5. Sensitivity Analysis to Selection of Immigrants

\begin{tabular}{|c|c|c|c|c|c|c|}
\hline & $\begin{array}{c}(1) \\
\text { Baseline } \\
\text { model }\end{array}$ & $\begin{array}{c}(2) \\
\text { Including } \\
\text { country-of- } \\
\text { ancestry Gini } \\
\end{array}$ & $\begin{array}{c}(3) \\
\text { Dropping } \\
\text { immigrants } \\
\text { from Russia } \\
\end{array}$ & $\begin{array}{c}(4) \\
\text { Dropping } \\
\text { immigrants } \\
\text { from Bosnia } \\
\end{array}$ & $\begin{array}{c}(5) \\
\text { Dropping } \\
\text { survey-country } \\
\text { Estonia } \\
\end{array}$ & $\begin{array}{c}(6) \\
\text { Dropping } \\
\text { survey-country } \\
\text { Latvia } \\
\end{array}$ \\
\hline $\begin{array}{l}\text { Experienced violence } \\
\text { (binary variable) }\end{array}$ & $\begin{array}{c}-0.237 * * * \\
(0.061)\end{array}$ & $\begin{array}{c}-0.218 * * * \\
(0.057)\end{array}$ & $\begin{array}{c}-0.2344 * * * \\
(0.0613)\end{array}$ & $\begin{array}{c}-0.2358 * * * \\
(0.0616)\end{array}$ & $\begin{array}{c}-0.2322 * * * \\
(0.0614)\end{array}$ & $\begin{array}{c}-0.2328 * * * \\
(0.0624)\end{array}$ \\
\hline $\begin{array}{l}\text { Number of times experienced violence } \\
\text { (continuous variable) }\end{array}$ & $\begin{array}{c}-0.889 * * * \\
(0.178)\end{array}$ & $\begin{array}{c}-0.918 * * * \\
(0.184)\end{array}$ & $\begin{array}{c}-0.8831 * * * \\
(0.1770)\end{array}$ & $\begin{array}{c}-0.8927 * * * \\
(0.1802)\end{array}$ & $\begin{array}{c}-0.8691 * * * \\
(0.1772)\end{array}$ & $\begin{array}{c}-0.8566 * * * \\
(0.1763)\end{array}$ \\
\hline Observations & 3,609 & 3,609 & 2.847 & 3.320 & 3.110 & 3.118 \\
\hline Host-country FE & $\mathrm{Y}$ & $\mathrm{Y}$ & $\mathrm{Y}$ & $\mathrm{Y}$ & $\mathrm{Y}$ & $\mathrm{Y}$ \\
\hline Educational attainment & $\mathrm{Y}$ & $\mathrm{Y}$ & $\mathrm{Y}$ & $\mathrm{Y}$ & $\mathrm{Y}$ & $\mathrm{Y}$ \\
\hline Gini index & $\mathrm{N}$ & $\mathrm{Y}$ & $\mathrm{N}$ & $\mathrm{N}$ & $\mathrm{N}$ & $\mathrm{N}$ \\
\hline
\end{tabular}

Notes: OLS coefficient estimates and their associated standard errors clustered by country of ancestry in parentheses.

Russia and Bosnia are the two countries of ancestry with more observations, while Estonia and Latvia are the two host countries with more observations.

$* * * \mathrm{p}<0.01, * * \mathrm{p}<0.05, * \mathrm{p}<0.1$ 
Table 6. Heterogeneity Analysis

\begin{tabular}{lcccccc}
\hline & $\begin{array}{c}\text { Low } \\
\text { educated }\end{array}$ & $\begin{array}{c}\text { High } \\
\text { educated }\end{array}$ & $\begin{array}{c}\text { No } \\
\text { children }\end{array}$ & Children & $\begin{array}{c}1^{\text {st }} \text {-generation } \\
\text { immigrants }\end{array}$ & $\begin{array}{c}2^{\text {nd }} \text {-generation } \\
\text { immigrants }\end{array}$ \\
\hline Experienced violence & $-0.235^{* * *}$ & -0.161 & -0.217 & $-0.224 * * *$ & $-0.212^{* *}$ & $-0.271^{*}$ \\
(binary variable) & $(0.066)$ & $(0.128)$ & $(0.161)$ & $(0.056)$ & $(0.099)$ & $(0.136)$
\end{tabular}

Number of times

$\begin{array}{lcccccc}\text { experienced violence } & -0.834 * * * & -0.885 * & -0.011 & -1.079 * * * & -0.945 * * * & -0.861 * * \\ \text { (continuous variable) } & (0.227) & (0.507) & (0.313) & (0.223) & (0.266) & (0.337)\end{array}$

\begin{tabular}{lcccccc}
\hline Observations & 2.275 & 1.334 & 683 & 2.926 & 2.008 & 1.601 \\
\hline Host-country FE & $\mathrm{Y}$ & $\mathrm{Y}$ & $\mathrm{Y}$ & $\mathrm{Y}$ & $\mathrm{Y}$ & $\mathrm{Y}$ \\
Educational attainment & $\mathrm{Y}$ & $\mathrm{Y}$ & $\mathrm{Y}$ & $\mathrm{Y}$ & $\mathrm{Y}$ & $\mathrm{Y}$ \\
\hline
\end{tabular}

Notes: OLS coefficient estimates and their associated standard errors clustered by country of ancestry in

parentheses. We estimate the baseline specification for each of the subgroups separately.

$* * * \mathrm{p}<0.01, * * \mathrm{p}<0.05, * \mathrm{p}<0.1$ 
Appendix 
Table A1. Country-of-Ancestry Variables: Definition and Descriptive Statistics

St. Dev.

across

Name

Definition

Mean

countries

of

ancestry

\begin{tabular}{ll}
\hline A. Gender Equality Measures \\
\hline Gender Gap $\quad$ Summarizes the position of women by considering economic opportunities,
\end{tabular}

Index (GGI) economic participation, educational attainment, political achievements, health and survival. The index ranges between 0 and 1 . Larger values point to a better position of women in society. Source: World Economic Forum, 2009 Report.

Economic
Participation
and
Opportunity
Index

Index based upon: (1) female over male labor force participation, (2) wage equality between women and men in similar jobs, (3) female over male earned income, (4) female over male legislators, senior officials and managers, and (5) female over male professional and technical workers. The index range between 0 and 1. Larger values point to a better position of women in society. This index is also elaborated for the World Economic Forum as part of the Gender Gap Index. Source: World Economic Forum, 2009 Report.

Educational Index based upon: (1) female over male literacy rate, (2) female over male Attainment primary-education enrollment, (3) female over male secondary-education Index enrollment, and (4) female over male tertiary-education enrollment. The index range between 0 and 1 . Larger values point to a better position of women in society. This index is also elaborated for the World Economic 2009 Report.

\begin{tabular}{lll}
\hline Health and & $\begin{array}{l}\text { Index based upon: (1) the gap between women and men's healthy life } \\
\text { Survival Index } \\
\text { expectancy, and (2) the sex ratio at birth, which aims to capture the } \\
\text { phenomenon of "missing women". The index range between 0 and 1. } \\
\text { Larger values point to a better position of women in society. This index is } \\
\text { also elaborated for the World Economic Forum as part of the Gender Gap } \\
\text { Index. Source: World Economic Forum, 2009 Report. }\end{array}$ \\
\hline $\begin{array}{l}\text { Political } \\
\text { Empowerment } \\
\text { Index }\end{array}$ & $\begin{array}{l}\text { Index based upon: (1) the ratio women to men with seats in parliament; (2) } \\
\text { the ratio of women to men in ministerial level and (3) the ratio of the } \\
\text { number of years with a woman as head of state to the years with a man. }\end{array}$ & 0.97 \\
& $\begin{array}{l}\text { The index range between 0 and 1. Larger values point to a better position } \\
\text { of women in society. This index is also elaborated for the World Economic }\end{array}$ & \\
& $\begin{array}{l}\text { Forum as part of the Gender Gap Index. Source: World Economic Forum, } \\
\text { 2009 Report. }\end{array}$ & \\
\hline FLFP & $\begin{array}{l}\text { Female labor force participation rates for women 15 years old and older. } \\
\text { We use the average between 2000 and 2014. Source: International Labour }\end{array}$ & 0.48 \\
& Organization. & 0.13 \\
\hline Aggregate IPV & $\begin{array}{l}\text { Lifetime IPV (\%). Source: The Gender, Institutions and Development } \\
\text { 2014 Data Base from OECD International Development. }\end{array}$ & \multirow{2}{*}{22.66} \\
\hline
\end{tabular}

Percent of The percentage of women who agree that a husband/partner is justified in women who beating his wife/partner under certain circumstances. Source: The Gender, agree IPV can Institutions and Development 2014 Data Base from OECD International be justified Development. This data base presents comparative data on gender equality. It has been compiled from secondary sources such as Gender Stats and the Human Development Report as well as from in-depth reviews of country case studies. These data help analyze women's economic empowerment and understand gender gaps in other key areas of development. Covering 160 countries, the GID-DB contains comprehensive information on legal, cultural and traditional practices that discriminate against women and girls.

\begin{tabular}{llll}
\hline Family Law & $\begin{array}{l}\text { Parental authority after divorce: Whether women and men have the same } \\
\text { Discrimination } \\
\text { right to be the legal guardian of a child during marriage. Parental authority } \\
\text { after divorce is presented as values ranging from 0 to 1, with 0 meaning } \\
\text { that the law guarantees the same rights for men and women and 1 meaning } \\
\text { that the law does not guarantee the same rights to men and women. }\end{array}$ & 0.10 & 0.26 \\
& $\begin{array}{l}\text { Source: The Gender, Institutions and Development 2014 Data Base from } \\
\text { OECD International Development. }\end{array}$ \\
\hline $\begin{array}{l}\text { Ownership } \\
\text { Discrimination }\end{array}$ & $\begin{array}{l}\text { Measure that codes women's vs men's legal and de facto rights with } \\
\text { respect to owning land, accessing credit (eg, bank loans), and owning } \\
\text { property other than land (eg, a house). Source: The Gender, Institutions }\end{array}$ & \\
&
\end{tabular}




\begin{tabular}{|c|c|c|c|}
\hline Name & Definition & Mean & $\begin{array}{l}\text { St. Dev. } \\
\text { across } \\
\text { countries } \\
\quad \text { of } \\
\text { ancestry }\end{array}$ \\
\hline \multicolumn{4}{|c|}{ B. Macro Variables } \\
\hline GDP per capita & $\begin{array}{l}\text { Gross Domestic Product per capita in real terms deflated with Laspeyres } \\
\text { price index. We average the 2003, } 2006 \text { and } 2009 \text { values. Source: Heston, } \\
\text { A., Summers, R. and Aten, B, Penn, World Table Version 7.0, Center for } \\
\text { International Comparisons of Production, Income and Prices at the } \\
\text { University of Pennsylvania, May 2011. }\end{array}$ & 14,751 & 12,533 \\
\hline Gini index & $\begin{array}{l}\text { Gini index measures the extent to which the distribution of income (or, in } \\
\text { some cases, consumption expenditure) among individuals or households } \\
\text { within an economy deviates from a perfectly equal distribution. a Gini index } \\
\text { of } 0 \text { represents perfect equality, while an index of } 100 \text { implies perfect } \\
\text { inequality. We took the average of all the GINI coefficients available from } \\
2001 \text { to } 2005 \text {. Germany had no GINI index available between } 2000-2005 \text { so } \\
\text { we used the } 2006 \text { value. Algeria was not listed as a country, we found a } \\
\text { GINI index of } 35.3 \text { online at mecometer.com. Source: World Bank } \\
\text { Development Indicators. }\end{array}$ & 0.37 & 0.09 \\
\hline Literacy rate & $\begin{array}{l}\text { Percentage of the population age } 15 \text { and above who can, with understanding, } \\
\text { read and write a short, simple statement on their everyday life. Generally, } \\
\text { 'literacy' also encompasses 'numeracy', the ability to make simple } \\
\text { arithmetic calculations. This indicator is calculated by dividing the number } \\
\text { of literates aged } 15 \text { years and over by the corresponding age group } \\
\text { population and multiplying the result by } 100 \text {. We averaged the values } \\
\text { between } 2000 \text { and } 2007 \text { and expressed the result as a value between } 0 \text { and } 1 . \\
\text { Source: World Bank Development Indicators. Missing values from the } \\
\text { World bank dataset were completed using CIA factbook as well as } \\
\text { http://world.bymap.org/LiteracyRates.html }\end{array}$ & 0.91 & 0.13 \\
\hline $\begin{array}{l}\text { Legal system } \\
\text { index }\end{array}$ & $\begin{array}{l}\text { Strength of legal rights index measures the degree to which collateral and } \\
\text { bankruptcy laws protect the rights of borrowers and lenders and thus } \\
\text { facilitate lending. The index ranges from } 0 \text { to } 10 \text {, with higher scores } \\
\text { indicating that these laws are better designed to expand access to credit. } \\
\text { Source: World Bank's Doing Business Reports and Warnock V., \& } \\
\text { Warnock, F. (2008). }\end{array}$ & 4.77 & 2.09 \\
\hline $\begin{array}{l}\text { Property rights } \\
\text { index }\end{array}$ & $\begin{array}{l}\text { A rating of property rights in each country (on a scale from } 0 \text { to } 100 \text { ). The } \\
\text { more protection private property receives, the higher the score. The score is } \\
\text { based, broadly, on the degree of legal protection of private property, the } \\
\text { extent to which the government protects and enforces laws that protect } \\
\text { private property, the probability that the government will expropriate private } \\
\text { property, and the country's legal protection private property. We averaged } \\
\text { the values between } 2000 \text { and } 2005 \text {. Source: Index of Economic Freedom. }\end{array}$ & 49.36 & 24.35 \\
\hline
\end{tabular}


Table A2. Incidence and Intensity of IPV Across Host Countries

\begin{tabular}{lccccc}
\hline Host country & Frequency & Percent & $\begin{array}{c}\text { Mean IPV Incidence } \\
\text { (fraction) }\end{array}$ & $\begin{array}{c}\text { Mean IPV } \\
\text { Intensity } \\
\text { (count) }\end{array}$ & $\begin{array}{c}\text { St. dev. IPV } \\
\text { Intensity } \\
\text { (count) }\end{array}$ \\
\hline Austria & 210 & 5.8 & 0.0762 & 0.2190 & 0.8693 \\
Belgium & 208 & 5.8 & 0.1154 & 0.2356 & 0.7908 \\
Croatia & 353 & 9.8 & 0.0397 & 0.0708 & 0.4498 \\
Czech Republic & 98 & 2.7 & 0.0714 & 0.1939 & 0.7820 \\
Denmark & 19 & 0.5 & 0.0000 & 0.0000 & 0.0000 \\
Estonia & 499 & 13.8 & 0.0220 & 0.0481 & 0.3664 \\
France & 122 & 3.4 & 0.0902 & 0.1885 & 0.8165 \\
Germany & 84 & 2.3 & 0.0238 & 0.0476 & 0.3438 \\
Hungary & 26 & 0.7 & 0.0769 & 0.1538 & 0.6127 \\
Ireland & 106 & 2.9 & 0.0472 & 0.1604 & 0.7945 \\
Italy & 10 & 0.3 & 0.1000 & 0.3000 & 0.9487 \\
Latvia & 491 & 13.6 & 0.0387 & 0.0957 & 0.5687 \\
Lithuania & 93 & 2.6 & 0.0323 & 0.1183 & 0.6892 \\
Luxembourg & 468 & 13.0 & 0.0556 & 0.1239 & 0.7000 \\
Malta & 46 & 1.3 & 0.0217 & 0.0217 & 0.1474 \\
Netherlands & 161 & 4.5 & 0.0683 & 0.1988 & 0.8861 \\
Portugal & 14 & 0.4 & 0.0000 & 0.0000 & 0.0000 \\
Slovakia & 71 & 2.0 & 0.0704 & 0.1690 & 0.6543 \\
Slovenia & 149 & 4.1 & 0.0134 & 0.0134 & 0.1155 \\
Spain & 113 & 3.1 & 0.0442 & 0.0708 & 0.3712 \\
Sweden & 138 & 3.8 & 0.0362 & 0.0580 & 0.3776 \\
United Kingdom & 130 & 3.6 & 0.0308 & 0.0846 & 0.6474 \\
Total & & & & & 0.6123 \\
\hline Notes: Stats & 3.609 & 100 & 0.0482 & 0.1119 & \\
\hline
\end{tabular}

Notes: Statistics based on the benchmark sample of 3.609 immigrants used in most of our estimations. Source: 2012 European Union (EU) Fundamental Rights Agency (FRA) household survey on violence against women. 
Table A3. Individual-Level Variables: Descriptive Statistics

\begin{tabular}{lcccc}
\hline \hline & $(1)$ & $(2)$ & $(3)$ & $(4)$ \\
Variables & Mean & St. Dev. & Min. & Max. \\
\hline IPV incidence in last 12 months & 0.0482 & 0.2142 & 0 & 1 \\
IPV counts in last 12 months & 0.1119 & 0.6123 & 0 & 8 \\
Age & 47.61 & 15.23 & 18 & 74 \\
Less than high school & 0.2807 & 0.4494 & 0 & 1 \\
University education & 0.2139 & 0.4101 & 0 & 1 \\
Married or cohabitating & 0.5946 & 0.4910 & 0 & 1 \\
Has children & 0.8108 & 0.3918 & 0 & 1 \\
Works in the labor market & 0.4796 & 0.4997 & 0 & 1 \\
Lives in rural area & 0.1992 & 0.3995 & 0 & 1 \\
Second-generation immigrant & 0.4436 & 0.4969 & 0 & 1 \\
Partner is university educated & 0.1521 & 0.3592 & 0 & 1 \\
Partner is employed & 0.4597 & 0.4984 & 0 & 1 \\
Is a minority & 0.2064 & 0.4048 & 0 & 1 \\
Has suffered discrimination & 0.1164 & 0.3207 & 0 & 1 \\
\hline \hline
\end{tabular}

Notes: Statistics based on the benchmark sample of 3.609 immigrants used in most of our estimations. Source: 2012 European Union (EU) Fundamental Rights Agency (FRA) household survey on violence against women. 
Appendix Table A4. IPV in the Host Country and Country-of-Ancestry Gender Equality Across Countries of Ancestry

\begin{tabular}{|c|c|c|c|c|c|c|c|c|}
\hline \multirow[b]{2}{*}{ Country of ancestry } & \multirow[b]{2}{*}{ Sample size } & \multicolumn{2}{|c|}{ In Host Country } & \multicolumn{5}{|c|}{ In Country of Ancestry } \\
\hline & & $\begin{array}{l}\text { IPV incidence } \\
\text { (binary) }\end{array}$ & $\begin{array}{l}\text { IPV intensity } \\
\text { (continuous) }\end{array}$ & GGI & $\begin{array}{c}\text { GGI } \\
\text { Economic } \\
\end{array}$ & $\begin{array}{l}\text { GGI } \\
\text { Education }\end{array}$ & GGI Health & $\begin{array}{l}\text { GGI } \\
\text { Political } \\
\text { power }\end{array}$ \\
\hline Norway & 21 & 0.048 & 0.048 & 0.8404 & 0.831 & 1.000 & 0.970 & 0.561 \\
\hline Finland & 57 & 0.053 & 0.053 & 0.8260 & 0.757 & 0.999 & 0.980 & 0.569 \\
\hline Ireland & 45 & 0.022 & 0.022 & 0.7773 & 0.741 & 1.000 & 0.970 & 0.399 \\
\hline Denmark & 19 & 0.211 & 0.053 & 0.7719 & 0.744 & 1.000 & 0.974 & 0.370 \\
\hline Spain & 25 & 0.080 & 0.040 & 0.7554 & 0.624 & 0.996 & 0.975 & 0.426 \\
\hline Germany & 204 & 0.059 & 0.029 & 0.7530 & 0.714 & 0.994 & 0.978 & 0.325 \\
\hline Belgium & 65 & 0.000 & 0.000 & 0.7509 & 0.710 & 0.991 & 0.979 & 0.324 \\
\hline UK & 129 & 0.093 & 0.031 & 0.7460 & 0.721 & 1.000 & 0.970 & 0.293 \\
\hline Netherlands & 45 & 0.133 & 0.067 & 0.7444 & 0.723 & 0.997 & 0.970 & 0.288 \\
\hline Argentina & 14 & 0.071 & 0.071 & 0.7187 & 0.602 & 0.995 & 0.980 & 0.298 \\
\hline Cabo Verde & 20 & 0.150 & 0.100 & 0.7180 & 0.555 & 0.837 & 0.976 & 0.145 \\
\hline Portugal & 212 & 0.193 & 0.085 & 0.7171 & 0.672 & 0.989 & 0.974 & 0.233 \\
\hline Belarus & 179 & 0.095 & 0.034 & 0.7140 & 0.721 & 0.998 & 0.979 & 0.143 \\
\hline Lithuania & 39 & 0.000 & 0.000 & 0.7132 & 0.756 & 0.989 & 0.980 & 0.128 \\
\hline Ecuador & 18 & 0.000 & 0.000 & 0.7072 & 0.599 & 0.988 & 0.976 & 0.267 \\
\hline Slovenia & 20 & 0.050 & 0.050 & 0.7047 & 0.723 & 0.998 & 0.975 & 0.123 \\
\hline Poland & 119 & 0.118 & 0.042 & 0.7037 & 0.653 & 0.999 & 0.979 & 0.184 \\
\hline Russia & 762 & 0.052 & 0.029 & 0.7036 & 0.736 & 0.999 & 0.979 & 0.100 \\
\hline France & 132 & 0.114 & 0.061 & 0.7025 & 0.661 & 1.000 & 0.980 & 0.169 \\
\hline Yugoslavia & 191 & 0.094 & 0.042 & 0.7005 & 0.687 & 0.993 & 0.970 & 0.147 \\
\hline Bosnia \& Herz. & 289 & 0.100 & 0.045 & 0.7002 & 0.661 & 0.994 & 0.980 & 0.142 \\
\hline Croacia & 76 & 0.000 & 0.000 & 0.6939 & 0.661 & 0.994 & 0.980 & 0.142 \\
\hline Colombia & 24 & 0.250 & 0.125 & 0.6927 & 0.694 & 0.996 & 0.979 & 0.102 \\
\hline China & 13 & 0.000 & 0.000 & 0.6881 & 0.693 & 0.981 & 0.929 & 0.150 \\
\hline Ukraine & 128 & 0.203 & 0.047 & 0.6869 & 0.707 & 1.000 & 0.976 & 0.065 \\
\hline Checoslovaquia & 60 & 0.150 & 0.067 & 0.6850 & 0.621 & 1.000 & 0.979 & 0.140 \\
\hline Romania & 98 & 0.102 & 0.051 & 0.6826 & 0.708 & 0.989 & 0.977 & 0.056 \\
\hline Slovakia & 98 & 0.194 & 0.071 & 0.6778 & 0.637 & 1.000 & 0.980 & 0.094 \\
\hline Italy & 123 & 0.098 & 0.049 & 0.6765 & 0.589 & 0.995 & 0.970 & 0.152 \\
\hline
\end{tabular}




\begin{tabular}{|c|c|c|c|c|c|c|c|c|}
\hline Bolivia & 11 & 0.000 & 0.000 & 0.6751 & 0.596 & 0.959 & 0.972 & 0.174 \\
\hline Hungary & 24 & 0.125 & 0.042 & 0.6720 & 0.689 & 0.990 & 0.978 & 0.031 \\
\hline Brazil & 14 & 0.000 & 0.000 & 0.6655 & 0.643 & 0.990 & 0.980 & 0.049 \\
\hline Indonesia & 25 & 0.280 & 0.120 & 0.6615 & 0.575 & 0.964 & 0.966 & 0.141 \\
\hline Surinam & 37 & 0.081 & 0.054 & 0.6407 & 0.449 & 0.985 & 0.974 & 0.154 \\
\hline Tunisia & 10 & 0.500 & 0.400 & 0.6266 & 0.450 & 0.966 & 0.962 & 0.128 \\
\hline India & 35 & 0.229 & 0.057 & 0.6155 & 0.403 & 0.837 & 0.931 & 0.291 \\
\hline Congo & 16 & 0.000 & 0.000 & 0.6108 & 0.541 & 0.859 & 0.961 & 0.083 \\
\hline Algeria & 33 & 0.455 & 0.121 & 0.6052 & 0.467 & 0.953 & 0.966 & 0.035 \\
\hline Turkey & 64 & 0.359 & 0.125 & 0.5876 & 0.386 & 0.912 & 0.975 & 0.077 \\
\hline Morocco & 104 & 0.365 & 0.144 & 0.5767 & 0.408 & 0.861 & 0.971 & 0.067 \\
\hline \multirow[t]{2}{*}{ Pakistan } & 11 & 0.000 & 0.000 & 0.5465 & 0.306 & 0.770 & 0.956 & 0.154 \\
\hline & 3,609 & 0.112 & 0.048 & 0.6936 & 0.670 & 0.986 & 0.976 & 0.168 \\
\hline
\end{tabular}


Table A5. Cross-Correlations: Host-Country IPV and Country-of-Ancestry Gender Equality

\begin{tabular}{|c|c|c|c|c|c|c|c|c|c|c|c|}
\hline & \multicolumn{2}{|c|}{ In Host Country } & \multicolumn{9}{|c|}{ In Country of Ancestry } \\
\hline & $\begin{array}{c}\text { IPV } \\
\text { incidence }\end{array}$ & $\begin{array}{c}\text { IPV } \\
\text { intensity }\end{array}$ & GGI & $\begin{array}{l}\text { GGI } \\
\text { Eco } \\
\text { Opp }\end{array}$ & $\begin{array}{l}\text { GGI } \\
\text { Educ }\end{array}$ & $\begin{array}{l}\text { GGI } \\
\text { H\&S }\end{array}$ & $\begin{array}{c}\text { GGI } \\
\text { Pol }\end{array}$ & FLFP & IPV & $\begin{array}{c}\% \\
\text { women } \\
\text { agree } \\
\text { IPV }\end{array}$ & $\begin{array}{c}\text { Family } \\
\text { Law } \\
\text { Discr }\end{array}$ \\
\hline Gender Gap Index (GGI) & -0.0889 & -0.0806 & 1 & & & & & & & & \\
\hline Economic Opportunity & -0.0994 & -0.1019 & 0.807 & 1 & & & & & & & \\
\hline Educational Attainment & -0.0759 & -0.0753 & 0.665 & 0.795 & 1 & & & & & & \\
\hline Health and Survival & -0.0393 & -0.0318 & 0.287 & 0.436 & 0.521 & 1 & & & & & \\
\hline Political Empowerment & -0.0351 & -0.0231 & 0.721 & 0.212 & 0.127 & -0.15 & 1 & & & & \\
\hline FLFP & -0.0750 & -0.0752 & 0.536 & 0.726 & 0.484 & 0.269 & 0.112 & 1 & & & \\
\hline IPV & 0.0360 & 0.0303 & -0.37 & -0.30 & -0.32 & -0.03 & -0.25 & -0.18 & 1 & & \\
\hline$\%$ women agree with IPV & 0.0250 & 0.0138 & -0.46 & -0.30 & -0.53 & -0.37 & -0.29 & 0.045 & 0.294 & 1 & \\
\hline Family Law Discrimination & 0.0653 & 0.0487 & -0.44 & -0.47 & -0.56 & -0.33 & -0.15 & -0.28 & 0.135 & 0.294 & 1 \\
\hline
\end{tabular}

Notes: This table displays Pearson correlations between variables. Statistics based on the benchmark sample of 3.609 immigrants used in most of our estimations. 
Figure A.1. Raw Average Number of IPV Events among Immigrants and Gender Equality in their Countries of Ancestry without Outlier (Tunisia)

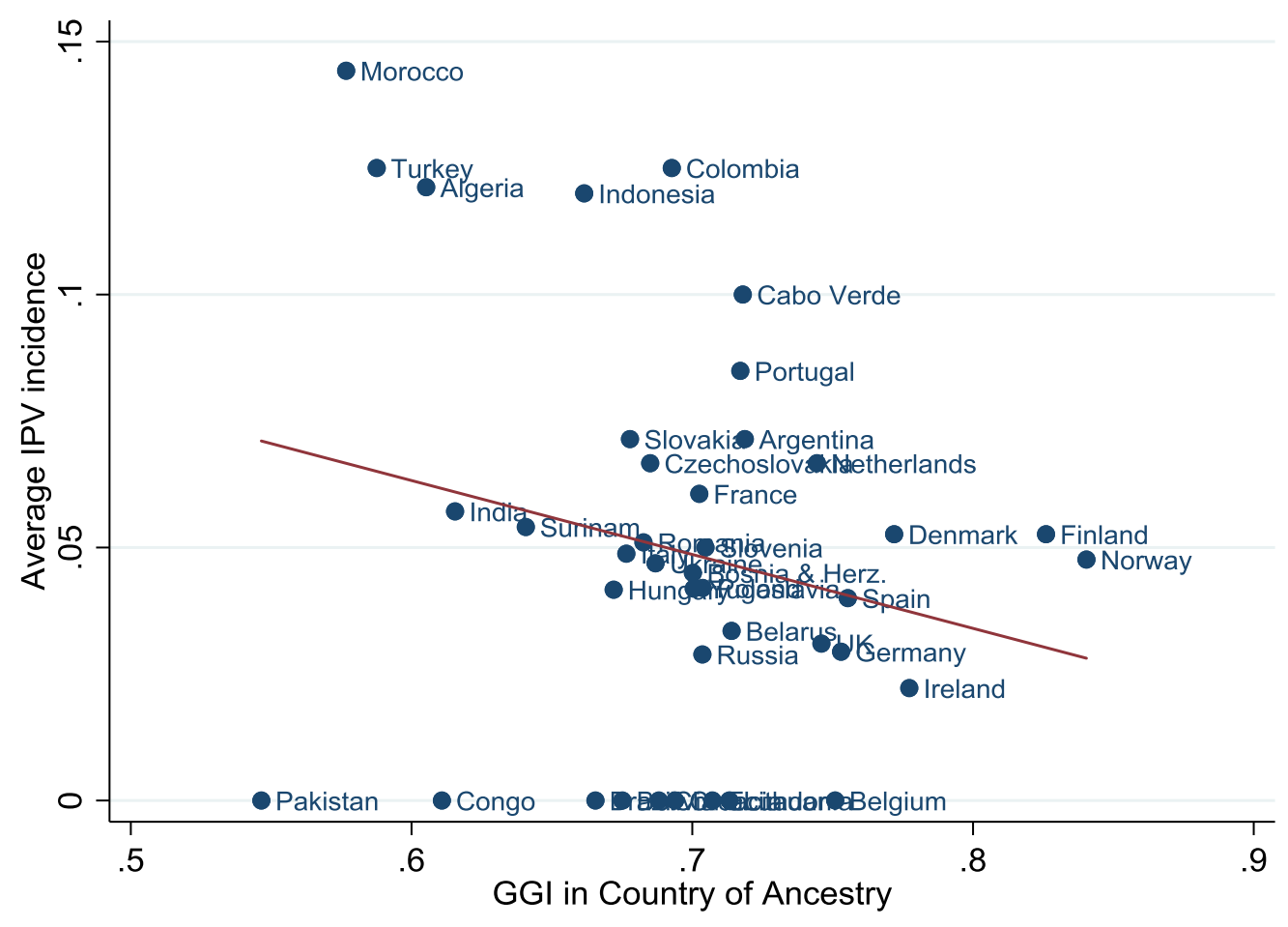

Notes: Appendix Figure A.1 displays the correlation between the raw count of IPV incidents among immigrants and second generation (during the previous 12 months), and the GGI in their countries of ancestry. Each variable is an average by country-of-ancestry. The regression line has a slope of -0.1461 with a standard error of 0.1022 . 